\title{
Dysphagia and Dysarthria in Children with Neuromuscular Diseases, a Prevalence Study
}

\author{
Mieke Kooi-van Es ${ }^{\mathrm{a}, \mathrm{b}}{ }^{*}$, Corrie E. Erasmus ${ }^{\mathrm{c}}$, Bert J.M. de Swart ${ }^{\mathrm{d}}$, Nicoline B.M. Voet ${ }^{\mathrm{a}, \mathrm{d}}$, \\ Philip J. van der Wees ${ }^{\mathrm{e}}$, Imelda J.M. de Groot ${ }^{\mathrm{d}}$, Lenie van den Engel-Hoek ${ }^{\mathrm{d}}$ and studygroup \\ Dutch pediatric rehabilitation centers ${ }^{1}$ \\ ${ }^{\mathrm{a}}$ Rehabilitation Centre Klimmendaal, Arnhem, The Netherlands \\ ${ }^{\mathrm{b}}$ Radboud University Medical Center, Radboud Institute for Health Sciences, Department \\ of Rehabilitation, Nijmegen, The Netherlands \\ ${ }^{\mathrm{c}}$ Radboud University Medical Centre, Department of Pediatric Neurology - Amalia Children's \\ Hospital, Nijmegen, The Netherlands \\ ${ }^{\mathrm{d}}$ Radboud University Medical Center, Department of Rehabilitation, Nijmegen, The Netherlands \\ ${ }^{\mathrm{e}}$ Radboud University Medical Center, Department of Rehabilitation and IQ Healthcare, Nijmegen, \\ The Netherlands
}

\begin{abstract}
.
Background: Dysphagia and dysarthria are frequently described in pediatric neuromuscular diseases (pNMD). The consequences can be substantial: failure to thrive, malnutrition, aspiration pneumonia, or communication problems. Early detection and identification of risk factors and etiology support preventing complications and morbidity, including impact on quality of life. Information about the prevalence of dysphagia and dysarthria in pNMD is scarce.

Objective: To describe the pooled prevalence of dysphagia and dysarthria in pNMD in the Netherlands. In addition, we describe the prevalence of dysphagia and dysarthria each, and the prevalence of chewing (oral) and swallowing problems per diagnostic group, based on their anatomic origin.

Methods: Data were collected from 295 children (mean age 11;0 years, range 2;6-18;0) with pNMD in 12 hospitals and rehabilitation centers in the Netherlands. A speech language therapist established whether dysphagia and dysarthria were present or not.

Results: In almost all the 14 diagnostic groups of pNMD, dysphagia and dysarthria were present. Pooled overall prevalence of dysphagia and dysarthria was $47.2 \%$ and $31.5 \%$, respectively. Of 114 children with dysphagia, $90.0 \%$ had chewing problems, $43.0 \%$ showed swallowing problems and $33.3 \%$ showed both chewing and swallowing problems.
\end{abstract}

\footnotetext{
${ }^{*}$ Correspondence to: Mieke Kooi-van Es, Rehabilitation Centre Klimmendaal, Heijenoordseweg 5, 6813 GG Arnhem, The Netherlands. Tel.: +3126 4838336, E-mail: m.kooi@klimmendaal.nl. ORCID ID: 0000-0002-4841-4478

${ }^{1}$ Members of the Study Group Dutch pediatric rehabilitation centers: W. Faber, Y. Stel, H. Herweijer (Revalidatie Friesland Centre for Rehabilitation, Beetsterzwaag); M. Quint, M. van Oirschot (Libra Revalidatie \& Audiologie, Eindhoven); N. Biegel-Slappendel, I. van der Ham (Rijndam Kinderrevalidatie,
} \begin{tabular}{l}
\hline Rotterdam); A. Bulsink (VieCuri, Venlo), E. Overdiep (Breda- \\
college, Breda); M. van Gerven (Radboudumc, Nijmegen), A. \\
van Daal (Reade, Amsterdam); S. Hendriksen (De Hoogstraat, \\
Utrecht); I. Taling (Merem, Huizen), M. Kraak (Heliomare, Wijk \\
aan zee), M. van den Hove, S. Franssen (Rehabilitation Centre \\
Klimmendaal, Arnhem).
\end{tabular} 
Conclusions: The overall pooled prevalence of dysphagia and dysarthria was high in the population of pNMD. It can be argued that periodic monitoring of dysphagia and dysarthria and early referral to a speech language therapist should be a necessity from the start of the diagnosis in the whole pNMD population.

Keywords: Dysphagia, dysarthria, neuromuscular diseases, children, prevalence

\section{INTRODUCTION}

Most neuromuscular diseases (NMD) are rare, their prevalence is not exactly known and differs per country. Pediatric NMD (pNMD) are classified by anatomic level: 1 . the ventral horn, 2 . the radix, 3 . the peripheral nerve, 4 . the neuromuscular junction, 5. the muscle.

In pNMD problems with eating, swallowing (i.e. dysphagia) and speech (i.e. dysarthria) are frequently described [1]. These problems can cause severe complications having a negative impact on health, well-being and social participation. Symptoms do not always appear to the same extent and at the same time in the child's development and through the course of the disease [2]. In addition, parents or caregivers are often not aware of the symptoms, which can develop gradually, and are often not aware of the risks and possibilities for treatment [3-5]. Early recognition and identification of risk factors and etiology might help prevent complications and morbidity and could improve quality of life $[2,4,6,7]$. Timely screening and referral of children at risk to a speech language therapist is important $[8,9]$. However, information about the prevalence of dysphagia and dysarthria in pNMD is scarce and data on chewing and swallowing problems is lacking. This information can give insight in a disease course, give help in optimal monitoring of the course and can give direction to new studies about interventions [10].

There are approximately 600 various NMD's that are acquired or inherited. Although varying in etiology and severity, (progressive) muscle weakness is the most common clinical feature.

Dysphagia in pNMD is mostly caused by weakness of the oral, facial and pharyngeal muscles and is often characterized by chewing and swallowing problems (oral and pharyngeal), that might result in prolonged mealtimes, and oral and/or pharyngeal residue [3, 11-14]. These problems are sometimes complicated, in varying degrees, by impairments such as limited mouth opening, inability to close the mouth due to malocclusions, or structural abnormalities of the tongue $[1,15,16]$. All this may lead to significant morbidity such as failure to thrive, malnutrition, choking, and aspiration [2,4]. Furthermore, dysphagia may negatively impact parent-child relationships, may need changes to lifestyle and to future plans of children and their parents. In addition, not being able to eat a meal in the social context may lead to isolation and exclusion [17-19].

The muscle weakness also induces dysarthria, a motor speech disorder causing problems on different levels: weak breathing, limited mouth opening and/or lip closure and disturbed oral control [5, 20-23]. These are evidently ingredients for communication difficulties with diminished performance in social situations and negative impact on the quality of life of children with pNMD [24-26].

In adults with NMD, a prevalence of dysphagia of $36-58 \%$ and of dysarthria of $46-62 \%$ was found [27]. In children with NMD, the prevalence rates of dysphagia and dysarthria are scarcely available; only in spinal muscular atrophy (SMA) II and III (45\%) [2] and myotonic dystrophy (52\%) [28] the prevalence of dysphagia has been described. The prevalence of dysarthria is only known in congenital and juvenile myotonic dystrophy (resp. 100\% and 79\%) [9]. Aspects of dysarthria has been described in literature in congenital myopathy [20], Duchenne muscular dystrophy (DMD) [29] and SMA [2, 30].

The goal of this study is to describe the pooled prevalence of dysphagia and dysarthria in pNMD in the Netherlands. In addition, we describe the overall pooled prevalence of dysphagia and dysarthria, and the prevalence of chewing (oral) and swallowing problems per diagnostic group.

\section{METHODS}

A multi-center cross-sectional design was used to describe the prevalence of dysphagia and dysarthria in pNMD. This study was approved by the Committee on Research Involving Human Subjects of Arnhem and Nijmegen (nr. 2015-1956). The Strobe Statement-checklist of observational cross-sectional studies was followed [31]. 


\section{Participants}

In the Netherlands, most children with an NMD are monitored annually by a rehabilitation physician or pediatric neurologist. To yield a representative sample of the pNMD population, 12 out of 26 Dutch rehabilitation centers and (university) hospitals known having a pNMD-team participated in the data collection. We included centers and hospitals when i) their speech language therapist (SLT) was involved in the Dutch working group 'Speech language therapy in children with neuromuscular diseases'; ii) their SLT was experienced in diagnosing pediatric dysphagia and dysarthria; iii) their internal medical ethical committee and/or research board approved the participation. Eight centers declined participation due to organizational problems (mostly time lack). A flowchart and a map displaying the inclusions and spread throughout the Netherlands of the participating centers is shown in Fig. 1.

Between October 2015 and December 2017, each of the participating centers included all eligible consecutive outpatients in a one-year-period if a patient i) was diagnosed with pNMD by a pediatric neurologist; (ii) was aged $\geq 2$ and $<18$ years; and (iii) the parent signed the informed consent.

Only the child's first visit in this one-year period counted. Children were excluded if they were having a (sub) acute auto-immune pNMD, for example Guillain Barre Syndrome (GBS).

\section{Assessment}

We used the Diagnostic list of Dysphagia and Dysarthria in pNMD (DDD-pNMD) [29], a Dutch instrument, to assess and diagnose dysphagia and/or dysarthria in children with NMD. The DDD-pNMD exists of four parts: 1) a screening part for the physician (Screeninglist Physician); 2) a questionnaire for parents; 3) a screening part for the speech language therapist (SLT); and 4) a diagnostic part for the SLT (see Fig. 2).

The Screeninglist Physician is a short screening instrument, consisting of nine broad yes/no-questions to be answered by parents/caregivers or by the young adult patient: seven questions on feeding and swallowing, and two questions on speech and communication. The questions are related to often reported complaints in pNMD [1]. The Screeninglist Physician has a sensitivity of $88 \%$ and identifies children at risk for dysphagia and/or dysarthria [32].
The parent questionnaire consists of anamnestic yes/no-questions about chewing, swallowing, eating and communication.

The screening part for the SLT aims to make an initial inventory of the current possibilities and signaled problems with regard to posture, anatomy, structure and movement of the articulation organs, saliva control, eating, drinking, chewing, swallowing, speech intelligibility and communication.

The diagnostic part for the SLT consists of more comprehensive assessment items concerning (a) posture, (b) oral and facial anatomy, structure, movement and sensibility, (c) saliva control, (d) eating, drinking, chewing, swallowing, and (e) speech and communication. Items are based on the Dysphagia Disorder Survey [33], measurement of the maximum voluntary mouth opening [16], masseter muscle tension [34], dysphagia limits [35], and the Radboud Dysarthria Assessment [36]. All items are scored by the SLT on a 4-point-scale ranging from $0=$ normal to $3=$ severe problems/impossible. Interpretation of the DDDpNMD requires specific SLT knowledge in the field of neurological swallowing disorders and speech in children. Final diagnosis of dysphagia and/or dysarthria is made by the SLT, considering information gathered by all parts of the DDD-pNMD in combination with clinical reasoning.

In this research, we only involved SLTs who were experienced in pNMD, in diagnosing pediatric dysphagia and dysarthria, and who were instructed and coached in the proper use of the DDD-pNMD.

\section{Data collection}

The physicians administered the Screeninglist Physician of the DDD-pNMD in all children with NMD who visited one of the outpatient clinics. The physician referred the children to the SLT if the screening turned out positive and/or if referral was part of their standard procedure (Fig. 3). An SLT experienced in pNMD used the diagnostic part of the DDD-pNMD to establish diagnosis of dysphagia and/or dysarthria. This was done for all children referred to the SLT. The SLT was asked to give an overall conclusion in terms of the presence 'yes' or 'no' of dysphagia and dysarthria. In case of dysphagia, nominal data on problems with chewing, swallowing (present/not present) were collected.

Data on age, gender, medical diagnosis (type and, if possible, stadium of disease for the different diagnostic groups of pNMD), Screeninglist Physician-score and SLT diagnosis were collected. 

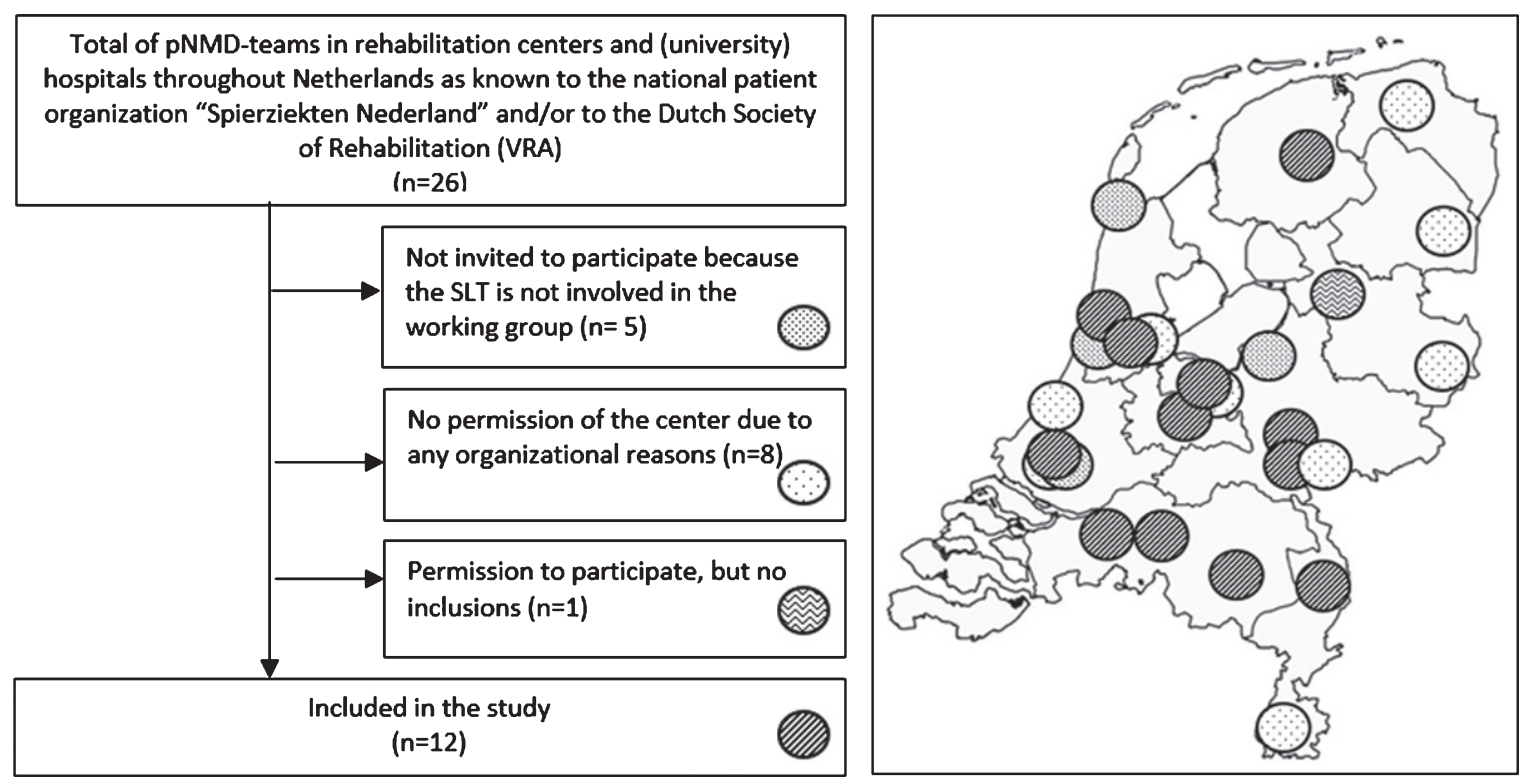

Fig. 1. Flow diagram and the spread of the centers over the Netherlands: $\mathrm{pNMD}=$ pediatric neuromusculair diseases.

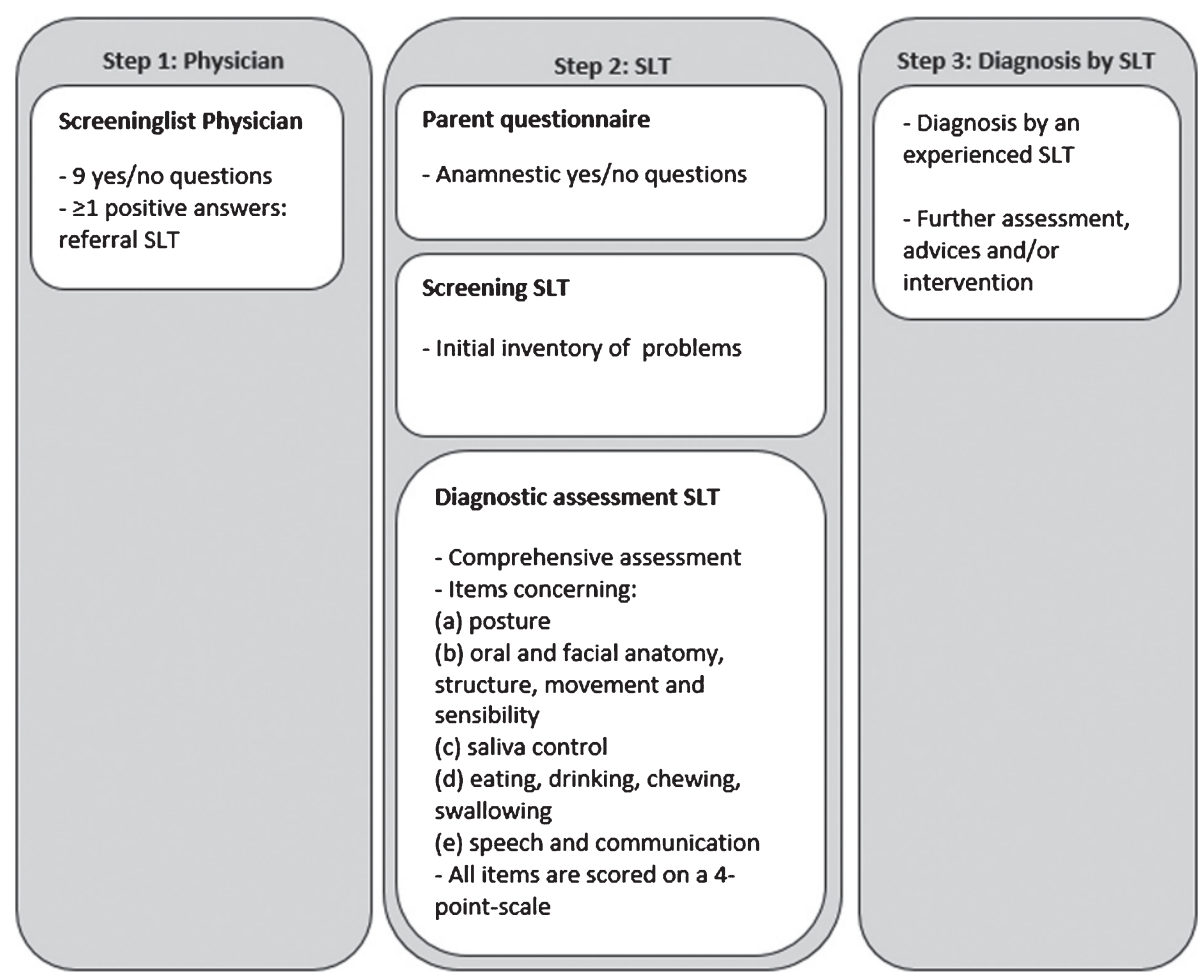

Fig. 2. DDD-pNMD parts. SLT $=$ Speech language therapist.

\section{Statistical methods}

Prevalence rates of dysphagia (broken down for chewing and swallowing problems) and dysarthria were calculated for each diagnostic group. We expected that the patients were unequally distributed across disease categories, so we used a weighting factor for a representative (pooled) total prevalence. 


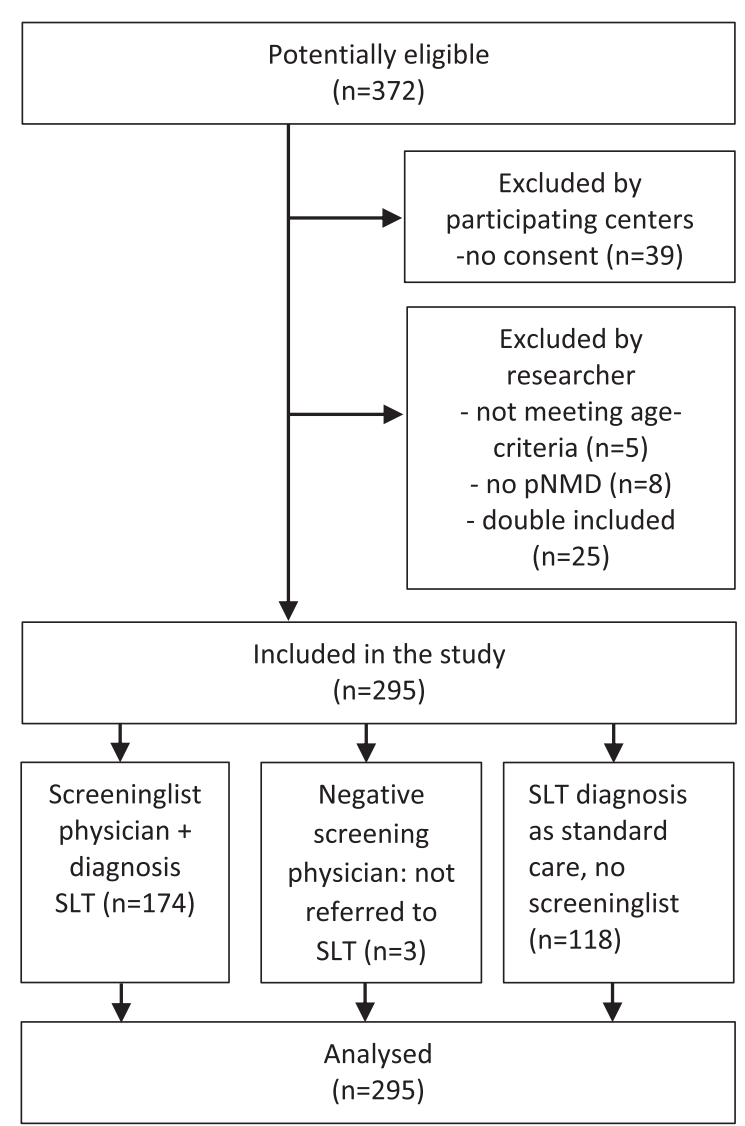

Fig. 3. Flow diagram of included participants $(n=295)$.

We estimated this pooled total prevalence rates as follows [27]: The total group of 295 children with pNMD was first categorized in 14 different diagnostic groups based on the anatomic origin of the disorder [1]. Prevalence rates of dysphagia and dysarthria were then calculated for each diagnostic group. After that, per diagnostic group, the weights were calculated (dependent on the size of the group and the prevalence within the group: $($ prev $*(1-$ prev $)) * N)$. The calculated weight was then multiplied by the prevalence, resulting in the calculated weighted prevalence for each diagnostic group ( prev $*$ weight). To calculate pooled prevalence, the total sum of weighted prevalence was divided by the total sum of all weights $\left(\frac{\sum \operatorname{prev} *((\operatorname{prev} *(1-\text { prev })) * N)}{\sum((\operatorname{prev} *(1-\operatorname{prev})) * N)}\right)$ and $95 \%$ confidence intervals were calculated. All calculations were performed with SPSS 23 (IBM SPSS Statistics, Chicago, IL) and Microsoft Excel 2013.

\section{RESULTS}

\section{Participants/descriptive data}

Of 372 potential eligible outpatients, 295 were included for analysis (see Fig. 3). In three cases, children were not referred to the SLT after a negative screening. In these cases, no dysphagia and/or dysarthria were assumed. In 118 children (of 295), the physician referred the child directly to the SLT for assessment without administering the Screeninglist Physician. The age of the children ranged from 2;6 to $18 ; 0$ years (mean $11 ; 0$, SD 4.0 ), see Table 1 for characteristics of the participants.

\section{Outcome data/ main results}

In all pNMD, except hereditary sensory and autonomic neuropathy type II, dysphagia and dysarthria were present, although there was a wide range of prevalence. Pooled overall prevalence of dysphagia was $47.2 \%$ and pooled overall prevalence of dysarthria was $31.5 \%$. Prevalence per diagnostic group is depicted in Table 2.

Dysphagia was diagnosed in 143 children. In $79.7 \%$ children of this group $(n=114)$ additional information about the type of problem (i.e. chewing and/or swallowing problems) was available. Of these 114 children $90.0 \%$ had chewing problems, $43.0 \%$ showed swallowing problems and $33.3 \%$ showed a combination of the two problems. For the percentages of the chewing and swallowing problems per diagnostic group and for the whole group $(n=114)$, see Fig. 4.

\section{DISCUSSION}

This study is the first to show that dysphagia is prevalent in almost half of pediatric neuromuscular diseases (pNMD), with an overall pooled prevalence of $47.2 \%$. For dysarthria, an overall pooled prevalence of $31.5 \%$ was found. The prevalence rates observed among disease categories differs from the pooled data. Analysis of 114 children with dysphagia shows that $90.0 \%$ had chewing problems, $43.0 \%$ showed swallowing problems and $33.3 \%$ showed both problems.

Although prevalence of pNMD could be different between geographical area's or between ethnic groups, we expect that the general finding of a high overall pooled prevalence does not differ across countries to a large extent. This high prevalence can 
Table 1

Characteristics of the participants $(\mathrm{N}=295)$

\begin{tabular}{|c|c|c|c|c|c|}
\hline & $\begin{array}{l}\text { Diagnostic groups based } \\
\text { on anatomical area }\end{array}$ & & Gender & & $\begin{array}{c}\text { Mean age } \\
\text { years; } \\
\text { months }(\mathrm{SD})\end{array}$ \\
\hline $\begin{array}{l}\text { Total } \\
\text { Age range in } \\
\text { years; months } \\
\text { (mean in years; } \\
\text { months, SD) }\end{array}$ & & $\begin{array}{c}\text { Total group } \mathrm{N}(\%) \\
295 \\
2 ; 6-18 ; 0 \\
(11 ; 0,4.0)\end{array}$ & $\begin{array}{c}\text { Male } \\
203 \\
2 ; 6-18 ; 0 \\
(10 ; 11,4.1)\end{array}$ & $\begin{array}{c}\text { Female } \\
92 \\
2 ; 6-18 ; 0 \\
(11 ; 1,3.9)\end{array}$ & $11 ; 00(4.0)$ \\
\hline \multirow[t]{8}{*}{ NMD, $n(\%)$} & Anterior horn cell & $29(9.8)$ & 16 & 13 & $10 ; 0(4.7)$ \\
\hline & Nerve fiber & $24(8.1)$ & 17 & 7 & $12 ; 1(4.1)$ \\
\hline & Neuromuscular junction & $8(2.7)$ & 5 & 3 & $10 ; 11(2.4)$ \\
\hline & Muscle, divided into: & & & & \\
\hline & Muscular dystrophy & $125(42.3)$ & 108 & 17 & $11 ; 5(3.8)$ \\
\hline & Myotonic dystrophy & $26(8.8)$ & 14 & 12 & $10 ; 7(4.4)$ \\
\hline & Congenital myopathy & $63(21.4)$ & 32 & 31 & $10 ; 5(4.1)$ \\
\hline & Metabolic myopathy & $20(6.6)$ & 11 & 9 & $10 ; 1(4.0)$ \\
\hline
\end{tabular}

$\mathrm{NMD}=$ Neuromuscular diseases .

Table 2

Frequencies of dysphagia and dysarthria $(\mathrm{n}=295)$

\begin{tabular}{|c|c|c|c|c|c|c|c|c|}
\hline \multirow[t]{2}{*}{ Anatomical area } & \multirow[t]{2}{*}{ p-NMD } & & \multirow{2}{*}{$\begin{array}{c}\text { Total } \\
n\end{array}$} & \multirow{2}{*}{$\begin{array}{c}\text { Mean age } \\
\text { Years, } \\
\text { months (SD) }\end{array}$} & \multirow{2}{*}{$\begin{array}{c}\text { Dysphagia } \\
n\end{array}$} & \multicolumn{3}{|c|}{ Dysarthria } \\
\hline & & & & & & $\%$ & $n$ & $\%$ \\
\hline \multirow[t]{4}{*}{ Anterior horn cell } & Spinal Muscular Atrophy & SMA type I & 1 & $5 ; 6(\mathrm{n} / \mathrm{a})$ & 1 & 100 & 1 & 100 \\
\hline & & SMA type II & 19 & $11 ; 0(4.9)$ & 9 & 47 & 2 & 11 \\
\hline & & SMA type III & 6 & $8 ; 10(4.0)$ & 2 & 33 & 1 & 17 \\
\hline & & Variants (NOS) & 3 & $7 ; 7(4.1)$ & 2 & 67 & 3 & 100 \\
\hline \multirow[t]{2}{*}{ Nerve fibre } & $\begin{array}{l}\text { Hereditary Motor } \\
\text { Sensory Neuropathies }\end{array}$ & HMSN type II & 22 & $12 ; 2(4.2)$ & 5 & 23 & 4 & 18 \\
\hline & Autonomic Neuropathies & HSAN type II & 2 & $10 ; 11(2.7)$ & 0 & 0 & 0 & 0 \\
\hline Neuromuscular junction & Myasthenic diseases & Myasthenic syndrome & 8 & $10 ; 11(2.3)$ & 7 & 88 & 5 & 63 \\
\hline \multirow[t]{7}{*}{ Muscle } & Muscle dystrophy & Duchenne \& Becker & 96 & $11 ; 7(3.6)$ & 36 & 36 & 10 & 10 \\
\hline & & FSHD & 9 & $10 ; 8(3.7)$ & 3 & 33 & 4 & 44 \\
\hline & & Variants (NOS) & 20 & $11 ; 0(4.8)$ & 7 & 35 & 3 & 15 \\
\hline & Myotonic dystrophy & Congenital & 4 & $11 ; 1(2.9)$ & 4 & 100 & 4 & 100 \\
\hline & & Juvenile & 22 & $10 ; 6(4.6)$ & 14 & 64 & 14 & 64 \\
\hline & Congenital myopathy & & 63 & $10 ; 5(4.1)$ & 38 & 60 & 19 & 30 \\
\hline & Metabolic myopathy & & 20 & $10 ; 1(4.0)$ & 16 & 80 & 10 & 50 \\
\hline Total & & & 295 & & 143 & & 80 & \\
\hline $\begin{array}{l}\text { Pooled prevalence } \\
\text { (weighted) }\end{array}$ & & & & & 47.2 & & 31.5 & \\
\hline $95 \% \mathrm{CI}$ & & & & & $41.5-52.9$ & & $26.2-36.8$ & \\
\hline
\end{tabular}

SMA = spinal muscular atrophy, NOS = not otherwise specified, HMSN = hereditary motor sensory neuropathy, HSAN = hereditary sensory autonomic neuropathy, FSHD = facioscapulohumeral muscular dystrophy, $\mathrm{CI}=$ confidence interval.

therefore be a starting point in other countries or health settings to create more awareness of dysphagia and dysarthria in pNMD.

Some of our findings of prevalence rates are matching other studies. Chen et al. (2012) conducted a large $(n=108)$ cohort study of risk factors for feeding and swallowing problems in SMA II and III by analyzing questionnaires and found a prevalence of feeding and swallowing problems of $44.4 \%$, which equals our findings in SMA II and III (44\%) [2]. We found a $100 \%$-prevalence recording for dyspha- gia and dysarthria in congenital myotonic dystrophy, which is equal to the 100-percentage impaired intelligibility (related to dysarthria) in severe and mild congenital myotonic dystrophy type I (DM1) as found by Sjogreen et al. (2018). In childhood DM1, these authors found that $79 \%$ of the children had impaired intelligibility, related to dysarthria, which is comparable with the $64 \%$ we have found [9]. It should be noted that our study is not aiming to explore or explain the relation between dysarthria and intelligibility. 


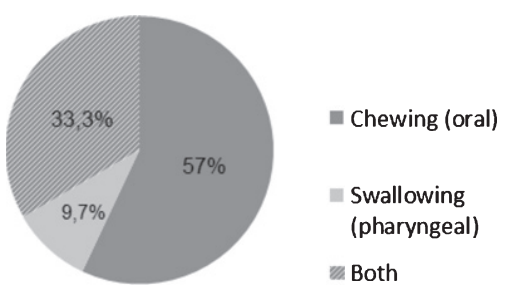

\begin{tabular}{lcc}
\hline & $\begin{array}{c}\text { Total } \\
(\mathrm{n}=114)\end{array}$ & $\%$ \\
\hline Chewing & 103 & 90,0 \\
\hline Swallowing & 49 & 43,0 \\
\hline Both & 38 & 33,3 \\
\hline
\end{tabular}

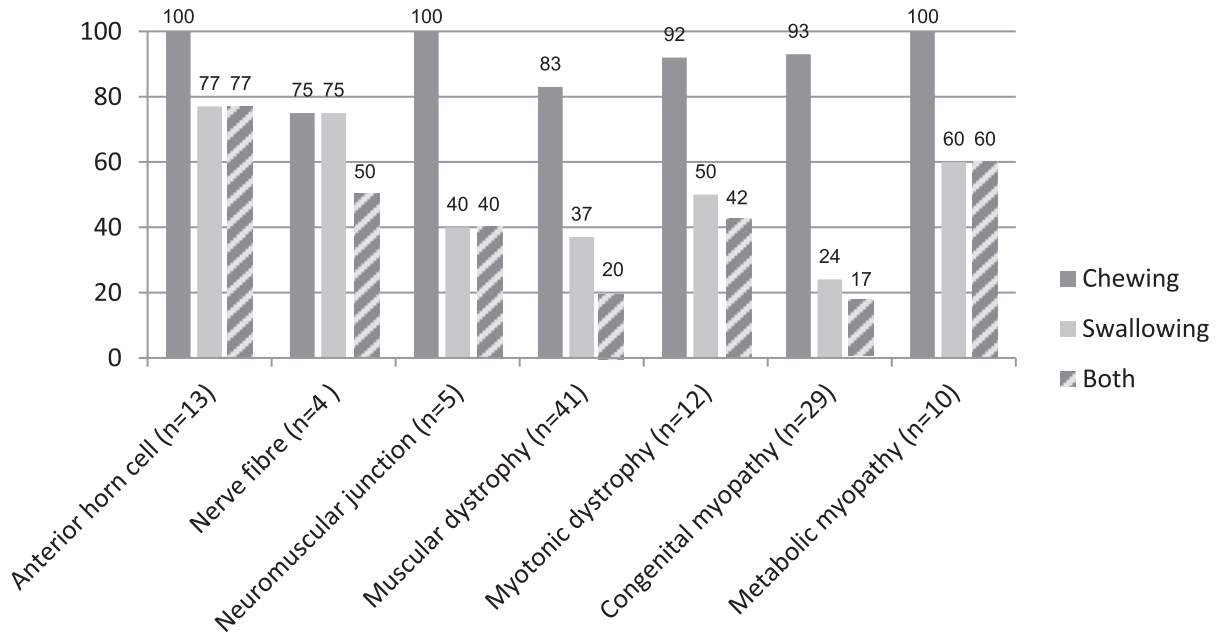

Fig. 4. Presence of chewing and swallowing problems in dysphagic pediatric neuromuscular diseases $(n=114)$.

However, in the review study of Audag et al. it was shown that not all studies had similar prevalence rates of dysphagia and dysarthria, probably due to different used study methods (different assessment methods, definitions of dysphagia [6] and/or study populations and sample sizes). For example, in Pompe disease, a metabolic pNMD with severe oral muscle weakness leading to hyper nasality in speech, a prevalence of dysarthria of $100 \%$ was found in literature [5, 22, 37]. In the current study we found a 50\%-dysarthriaprevalence in the metabolic NMD group, probably due to heterogeneity and included diagnoses with less severe oral muscle weakness.

Some studies showed lower prevalence rates. In a study by Pane (2006) $28 \%$ of 118 patients with DMD reported feeding problems, which is less than the $36 \%$ we found [15]. Sjogreen (2007) found a prevalence of $51.9 \%$ of eating problems in children and adolescents with myotonic dystrophy $(n=54)$, as assessed with a questionnaire [28]. This is lower than our findings in the congenital myotonic dystrophy patients $(100 \%$, $n=4)$ and juvenile myotonic dystrophy $(64 \%, n=22)$.

Both Sjogreen and Pane used questionnaires to describe the prevalence of dysphagia. The differences in prevalence compared to our study might be explained by their use of questionnaires, which points to self-reported problems that might give an underestimation.

Although no consensus exists on the best tool or specific protocol for evaluating dysphagia in pNMD [6], we suspect clinical examination is more sensitive than the often-used questionnaires. Knuijt et al. (2013) also found a discrepancy in prevalence between their study in adult NMD, probably explained by the assessment methods and underreported complaints and disabilities [27]. Overall feeding and swallowing difficulties in pNMD are frequently underrecognized as described by Hull et al. (2012) [3].

The strength of our study is that the data collection was done by the speech language therapist in combination with an initial screening by the physician, comparable with the study of Knuijt et al. (2013). We think that this method gives a more precise prevalence.

\section{Limitations}

We used observational instruments, because standardized assessment tools for pediatric dysphagia are lacking [6]. Instrumental tools like video fluoroscopic swallowing exams, which are considered gold 
standard, are too invasive for children if no signs of aspiration exist. Our research relied on clinical examiners to assess several variables leading to a diagnosis of dysphagia or dysarthria. To the best of the authors' knowledge, there is no gold standard for the noninstrumental assessment of dysphagia and dysarthria in children. The quality of the gathered information is dependent both on the skills of the examiners and the validity of the used assessment methods. There is no gold standard for the non-instrumental assessment of pediatric dysphagia and dysarthria. We have made several attempts to increase the objectivity of assessments. First, we used the DDD-pNMD, an instrument which was clear-cut designed to assess dysphagia and dysarthria in pNMD (Franssen, 2015). Second, all participating SLTs were members of the Dutch working group 'Speech language therapy in children with neuromuscular diseases' and have been involved in the development of the DDD-pNMD. Moreover, all participators of this working group were instructed and coached in the proper use of the instrument.

We conducted this study multi-central within a one-year period to increase the proportion of the overall population of the participation centers in this study and with that, optimize the generalizability. However, there is a possibility that children with milder disease phenotypes, who were not referred to a secondarylevel health service were missing in our study sample. Given the nature of pNMDs, we think these numbers are small.

In addition, dysphagia and dysarthria were measured at a single point in time across ages. This might be a limitation because there can be changes over time, due to normal development and/or the progressiveness of some of the disease categories, which was not measured. The influences of the seasons has not been taken into account in this study.

\section{CONCLUSION}

This study is the first describing the prevalence of dysphagia and dysarthria, using a standardized assessment, in a large group of children with pNMD. The overall pooled prevalence of dysphagia (47.2\%) and dysarthria $(31.5 \%)$ is high in the population of pNMD, and there are marked differences between different groups of diagnoses. So, physicians should be aware of possible dysphagia and/or dysarthria problems and refer all children with pNMD in an early stage to an SLT to minimize health risks. It can be argued that periodic monitoring of dysphagia and dysarthria should be a necessity from the start of the diagnosis in the whole pNMD population. We recommend to further explore the underlying mechanisms of dysphagia and dysarthria in these populations.

\section{ACKNOWLEDGMENTS}

The authors would like to thank the children and their parents for their participation, the (university) hospitals and rehabilitation centers for providing the data.

The authors received financial support for the research of this article by the JohannaKinderFonds, Arnhem, the Netherlands.

\section{CONFLICT OF INTEREST}

The authors have no conflict of interest to report

\section{REFERENCES}

[1] van den Engel-Hoek L, de Groot IJM, de Swart BJM, Erasmus CE. Feeding and swallowing disorders in pediatric neuromuscular diseases: An overview. Journal of Neuromuscular Diseases. 2015;2(4):357-69. doi: 10.3233/JND-150122.

[2] Chen YS, Shih HH, Chen TH, Kuo CH, Jong YJ. Prevalence and risk factors for feeding and swallowing difficulties in spinal muscular atrophy types II and III. J. Pediatr. 2012;160(3):447-51.

[3] Hull J, Aniapravan R, Chan E, Chatwin M, Forton J, Gallagher J, et al. British Thoracic Society guideline for respiratory management of children with neuromuscular weakness. Thorax. 2012;67:1-40. doi: 10.1136/thoraxjnl2012-201964.

[4] Philpot J, Bagnall A, King C, Dubowitz V, Muntoni F. Feeding problems in merosin deficient congenital muscular dystrophy. Arch. Dis. Child. 1999;80(6):542-47.

[5] van Gelder CM, van Capelle CI, Ebbink BJ, Moor-van Nugteren I, van den Hout JMP, Hakkesteegt MM, et al. Facial-muscle weakness, speech disorders and dysphagia are common in patients with classic infantile Pompe disease treated with enzyme therapy. J. Inherit. Metab. Dis. 2012;35(3):505-11. doi: 10.1007/s10545-011-9404-7.

[6] Audag N, Goubau C, Toussaint M, Reychler G. Screening and evaluation tools of dysphagia in children with neuromuscular diseases: A systematic review. Dev. Med. Child Neurol. 2016. doi: 10.1111/dmcn.13354.

[7] Prasse JE, Kikano GE. An overview of pediatric dysphagia. Clin. Pediatr. (Phila.). 2009;48(3):247-51. doi: 10.1177/0009922808327323.

[8] Birnkrant DJ, Bushby K, Bann CM. Diagnosis and management of Duchenne muscular dystrophy, Part 1: Diagnosis, and neuromuscular, rehabilitation, endocrine, and gastrointestinal and nutritional management (vol 17,pg 251, 2018). Lancet Neurol. 2018;17(6):495-95. doi: 10.1016/s14744422(18)30125-x.

[9] Sjogreen L, Martensson A, Ekstrom AB. Speech characteristics in the congenital and childhood-onset forms of myotonic dystrophy type 1. International Journal of Language \& Communication Disorders/Royal College of Speech \& Language Therapists. 2018;00(0):1-8. doi: 10.1111/1460-6984.12370. 
[10] Newman LA, Keckley C, Petersen MC, Hamner A. Swallowing function and medical diagnoses in infants suspected of dysphagia. Pediatrics. 2001;108(6):4. doi: 10.1542/peds.108.6.e106.

[11] Aloysius A, Born P, Kinali M, Davis T, Pane M, Mercuri E. Swallowing difficulties in Duchenne muscular dystrophy: Indications for feeding assessment and outcome of videofluroscopic swallow studies. Eur. J. Paediatr. Neurol. 2008;12(3):239-45. doi: 10.1016/j.ejpn.2007.08.009.

[12] van den Engel-Hoek L, Erasmus CE, van Hulst KCM, Arvedson JC, de Groot IJM, de Swart BJM. Children with central and peripheral neurologic disorders have distinguishable patterns of dysphagia on videofluoroscopic swallow study. J. Child Neurol. 2014;29(5):646-53. doi: 10.1177/0883073813501871.

[13] Willig TN, Paulus J, Saintguily JL, Beon C, Navarro J. Swallowing problems in neuromuscular disorders. Arch. Phys. Med. Rehabil. 1994;75(11):1175-81. doi: 10.1016/00039993(94)90001-9.

[14] Botteron S, Verdebout CM, Jeannet PY, Kiliaridis S. Orofacial dysfunction in Duchenne muscular dystrophy. Arch. Oral Biol. 2009;54(1):26-31. doi: 10.1016/ j.archoralbio.2008.07.012.

[15] Pane M, Vasta I, Messina S, Sorleti D, Aloysius A, Sciarra $\mathrm{F}$, et al. Feeding problems and weight gain in Duchenne muscular dystrophy. Eur. J. Paediatr. Neurol. 2006;10(56):231-36. doi: 10.1016/j.ejpn.2006.08.008.

[16] van Bruggen HW, van den Engel-Hoek L, van der Pol WL, de Wijer A, de Groot IJM, Steenks MH. Impaired mandibular function in Spinal Muscular Atrophy Type II: Need for early recognition. J. Child Neurol. 2011;26(11):1392-96. doi: $10.1177 / 0883073811407696$.

[17] Hewetson R, Singh S. The Lived Experience of Mothers of Children with Chronic Feeding and/or Swallowing Difficulties. Dysphagia. 2009;24(3):322-32. doi: 10.1007/s00455-009-9210-7.

[18] Craig GM, Scambler G, Spitz L. Why parents of children with neurodevelopmental disabilities requiring gastrostomy feeding need more support. Dev. Med. Child Neurol. 2003;45(3):183-88. doi: 10.1017/s0012162203000355.

[19] Remijn L, van den Engel-Hoek L, Satink T, de Swart BJM, Nijhuis-van der Sanden MWG. "Everyone sees you sitting there struggling with your food": Experiences of adolescents and young adults with cerebral palsy. Disabil. Rehabil. 2019;41(16):1898-905. doi: 10.1080/09638288.2018.1451923.

[20] Bagnall A, Al-Muhaizea MA, Manzur AY. Feeding and speech difficulties in typical congenital nemaline myopathy. Dev. Med. Child Neurol. 2006;48:29-29.

[21] Bushby K, Birnkrant D, Case L, Clemens P, Cripe L, Finkel R, et al. The diagnosis and management of Duchenne muscular dystrophy: Internationally generated care recommendations. Neuromuscul. Disord. 2009;19(8-9):640-41. doi: 10.1016/j.nmd.2009.06.300.

[22] Muller CW, Harrisson NJ, O'Grady G, Habakkuk Suarez A, Heller JH, Kishnani PS. Language and speech function in children with infantile Pompe disease. J. Pediatr. Neurol. 2009; 7:147-56.

[23] Wang CH, Bonnemann CG, Rutkowski A, Sejersen T, Bellini J, Battista V, et al. Consensus statement on standard of care for congenital muscular dystrophies. J. Child Neurol. 2010;25(12):1559-81. doi: 10.1177/0883073810381924.

[24] Johnson NE, Ekstrom AB, Campbell C, Hung M, Adams HR, Chen W, et al. Parent-reported multi-national study of the impact of congenital and childhood onset myotonic dystrophy. Dev. Med. Child Neurol. 2016;58(7):698-705. doi: $10.1111 / \mathrm{dmcn} .12948$.

[25] Johnson NE, Luebbe E, Eastwood E, Chin N, Moxley RT, Heatwole CR. The impact of congenital and childhood myotonic dystrophy on quality of life: A qualitative study of associated symptoms. J. Child Neurol. 2014;29(7):983-86. doi: $10.1177 / 0883073813484804$.

[26] Markham C, Van Laar D, Dean T. Development of a quality of life measure for children and young people with speech, language, and communication needs. EvidenceBased Communication Assessment and Intervention. 2011;5(4):216-25. doi: 10.1080/17489539.2012.688342.

[27] Knuijt S, Kalf JG, De Swart BJM, Drost G, Hendricks HT, Geurts ACH, et al. Dysarthria and dysphagia are highly prevalent among various types of neuromuscular diseases. Disabil. Rehabil. 2013; early online:1-5. doi: 10.3109/09638288.2013.845255.

[28] Sjogreen L, Engvall M, Ekstrom AB, Lohmander A, Kiliadiris $\mathrm{S}$, Tulinius M. Orofacial dysfunction in children and adolescents with myotonic dystrophy. Dev. Med. Child Neurol. 2007;49(1):18-22. doi: 10.1017/S0012162207000060.

[29] van den Engel-Hoek L, Erasmus CE, Hendriks JCM, Geurts $\mathrm{ACH}$, Klein WM, Pillen S, et al. Oral muscles are progressively affected in Duchenne muscular dystrophy: Implications for dysphagia treatment. J. Neurol. 2013;260(5):1295-303. doi: 10.1007/s00415-012-6793-y.

[30] van den Engel-Hoek L, Erasmus CE, van Bruggen HW, de Swart BJM, Sie LT, Steenks MH, et al. Dysphagia in spinal muscular atrophy type II: More than a bulbar problem? Neurology. 2009;73(21):1787-91. doi: 10.1212/WNL.0b013e3181c34aa6.

[31] von Elm E, Altman D, Egger M, Pocock S, Gøtzsche $\mathrm{P}$, Vandenbroucke $\mathrm{J}$. The strengthening the reporting of observational studies in epidemiology (STROBE) statement: Guidelines for reporting observational studies. J. Clin. Epidemiol. 2008;61(4):344-49. doi: 10.1016/ j.jclinepi.2007.11.008.

[32] Kooi M, Erasmus CE, Houwen S, de Groot IJM, Voet NBM, van den Engel-Hoek L. Early detection of dysphagia and dysarthria in children with neuromuscular disorders: Diagnostic accuracy of a Screeninglist for Physicians. J. Pediatr. Rehabil. Med. Accepted for publication. doi: 10.3233/ PRM-180569

[33] Sheppard JJ. Dysphagia Disorder Survey and Dysphagia Management Staging scale (Manual, Dutch translation by Vleugelers, R. en Penning, C.). 1 ed. Rotterdam: Faculteit Geneeskunde en Gezondheidswetenschappen; 2002.

[34] Ohara Y, Hirano H, Watanabe Y, Edahiro A, Sato E, Shinkai $\mathrm{S}$, et al. Masseter muscle tension and chewing ability in older persons. Geriatr. Gerontol. Int. 2013;13(2):372-77. doi: 10.1111/j.1447-0594.2012.00909.x.

[35] Ozdemirkiran T, Secil Y, Tarlaci S, Ertekin C. An EMG screening method (dysphagia limit) for evaluation of neurogenic dysphagia in childhood above 5 years old. Int. J. Pediatr. Otorhinolaryngol. 2007;71(3):403-07. doi: 10.1016/j.ijporl.2006.11.006.

[36] Knuijt S, Kalf JG, van Engelen BGM, de Swart BJM, Geurts $\mathrm{ACH}$. The Radboud Dysarthria Assessment: Development and Clinimetric Evaluation. Folia Phoniatrica Et Logopaedica. 2017;69(4):143-53. doi: 10.1159/000484556.

[37] Jones HN, Muller CW, Lin M, Banugaria SG, Case LE, Li JS, et al. Oropharyngeal dysphagia in infants and children with infantile Pompe disease. Dysphagia. 2010;25(4):27783. doi: 10.1007/s00455-009-9252-x. 